\title{
Quality of life and physical activity in an older working-age population
}

This article was published in the following Dove Press journal:

Clinical Interventions in Aging

4 October 2017

Number of times this article has been viewed

\section{Daniel Puciato' \\ Zbigniew Borysiuk' \\ Michał Rozpara ${ }^{2}$}

'Faculty of Physical Education and Physiotherapy, Opole University of Technology, Opole, ${ }^{2}$ Faculty of Physical Education, The Jerzy Kukuczka Academy of Physical Education in Katowice, Katowice, Poland
Correspondence: Daniel Puciato Faculty of Physical Education and Physiotherapy, Opole University of Technology, ul Prószkowska 76, 45-758 Opole, Poland

$\mathrm{Tel}+48774498000$

Email d.puciato@po.opole.pl
Objective: Physical activity can be an effective means of prevention and therapy of many psychosomatic disorders. It can also have a significant impact on the quality of life of older working-age people. The aim of the present study was to assess the relationships between quality of life and physical activity in older working-age people from Wrocław, Poland.

Materials and methods: The study group comprised 1,013 people, including 565 women and 448 men, aged 55-64 years (59.1 \pm 2.9 years). The study took form of a questionnaire survey. The participants assessed their physical activity and quality of life using the International Physical Activity Questionnaire Short Version (IPAQ-SF) and the World Health Organization Quality of Life (WHOQOL-BREF), respectively.

Results: The highest mean indices of general quality of life, perceived health status, and quality of life in the physical, psychological, social, and environmental domains were shown by respondents whose intensity of physical activity was the highest. Moreover, the odds of high assessment of overall quality of life increased with respondents' higher levels of physical activity.

Conclusion: Quality of life improvement programs should also involve increased physical activity components.

Keywords: physical activity, IPAQ-SF, quality of life, WHOQOL-BREF, big city environment

\section{Introduction}

The issue of quality of life of older working-age people is highly significant. Results of some earlier studies indicate that decreased quality of life is often associated with the prevalence of psychosomatic and motor function disorders as well as with impaired social performance. ${ }^{1-4}$

An important determinant of quality of life is physical activity. Apart from lowering physical fitness and performance, ${ }^{5-7}$ insufficient physical activity can also increase the risk of muscle atrophy, sarcopenia, osteoporosis, type 2 diabetes, arterial hypertension, coronary heart disease, and certain types of cancer. ${ }^{8-19}$ Studies indicate negative consequences of hypokinesis for mental health and intellectual abilities, eg, cognitive disorders, increased anxiety, discomfort and low self-esteem, high stress levels, and sleeping disorders. ${ }^{20-25}$

Undertaking properly dosed physical activity allows older working-age people to maintain their physical and mental fitness at an appropriate level and enable effective performance of their professional duties. ${ }^{26,27}$ Halloway et $\mathrm{al}^{28}$ and Kirk-Sanchez and McGough $^{29}$ observed positive effects of exercise on brain health and cognitive performance in adult populations. Physical activity may therefore fulfill both preventive and rehabilitative functions in this particular age group. Physical exercises undertaken by people at this age can be regarded as interventions aimed at maintaining or improving 
their overall psychophysical fitness, proper functioning of the overloaded body, ${ }^{6,7,16,17,19,20}$ or full recovery after diseases, injuries, or fatigue states. ${ }^{9-12,21,22,25}$ In addition, the beneficial influence of physical activity on the functional autonomy of elderly people (usually declining with age) should be stressed. ${ }^{30}$

It must be noted that appropriate levels of physical activity are far from common among the elderly. Involutionary changes observed in elderly people together with the incidence of various ailments often lead to fairly limited physical activity in this age group. ${ }^{31-33}$

Potential links between quality of life and physical activity were subject to earlier studies, which showed that physically active individuals assessed some of their quality of life domains higher than their physically non-active counterparts. $^{34-41}$ Some authors even suggest that infirm persons who exercised regularly assessed their quality of life higher than healthy but physically non-active individuals. ${ }^{42}$ The volume of exercise is crucial here, since therapeutic effects of exercise can only be seen at a moderate or high level of performance. ${ }^{6,43}$ A few studies so far have examined relationships between quality of life and physical activity of older working-age persons, but they have focused on general populations or, in fact, on post-working-age individuals. ${ }^{34,36-38}$ The aim of the present article was to assess relationships between quality of life and physical activity in an older working-age population from Wrocław, Poland. Two main research questions were formulated:

1. Are general quality of life (GQOL), quality of life in its particular domains (physical domain [PHYD], psychological domain [PSYD], social domain [SD], environmental domain [ED]), and perceived health satisfaction determined differently by the physical activity level?

2. Are there relationships between the assessed quality of life and the level of physical activity among the studied population?

\section{Materials and methods}

A cross-sectional questionnaire survey was carried out in 2014 in Wrocław, Poland. The research project had been approved by the Commission of Bioethics of the University School of Physical Education in Wrocław. Before the start of the study, the minimum sample size was calculated using the following formula:

$$
\mathrm{n}=\frac{\mathrm{N}}{1+\frac{4 d^{2}(\mathrm{~N}-1)}{z_{\alpha}^{2}}}
$$

where $\mathrm{n}$ is the minimum sample size, $\mathrm{N}$ the size of the Wrocław working-age population, $d$ the maximum error of estimate, and $z_{\alpha}$ the critical value of normal distribution at the assumed confidence level.

The survey interviewers took part in a training session during which they were specifically instructed about the aims of the study, the structure of questionnaire forms, filling instructions, and the means of effective communication with respondents. The questionnaire survey took place in November 2014. The study group comprised 1,013 people (565 women and 448 men) aged 55-64 years (59.1 \pm 2.9 years), ie, $\sim 1 \%$ of the Wrocław population at this age. All participants were informed about the purpose and the course of the study and gave their written consent to participate. The questionnaire survey was carried out in the form of hall testing. The mean percent age of respondents who refused completing the questionnaire was $46 \%$.

The participants assessed their habitual physical activity using the International Physical Activity Questionnaire Short Version (IPAQ-SF). ${ }^{44}$ The IPAQ-SF comprises items assessing the frequency and duration of physical activity in three ranges of intensity: vigorous physical activity (VPA $=8.0$ metabolicequivalent $[\mathrm{MET}]$ ), moderate physical activity (MPA =4.0 METs), and low physical activity (LPA =3.3 METs) undertaken across a set of domains including leisure time, domestic and gardening (yard), and work-related and transport-related activities during a typical week of their life. On the basis of collected data on the frequency and duration of physical activity and estimated energy expenditure (EE) expressed in MET·min/week, the respondents were categorized into three groups according to their physical activity levels:

1. High physical activity level (HPAL) - meeting any one of the following criteria: 3 or more days of vigorous activity of at least $\mathrm{EE} \geq 1,500 \mathrm{MET} \cdot \mathrm{min} /$ week or 7 or more days of any combination of activities of three intensity ranges of at least $\mathrm{EE} \geq 3,000 \mathrm{MET} \cdot \mathrm{min} /$ week.

2. Moderate physical activity level (MPAL) -3 or more days of vigorous activity of at least 20 minutes/day, 5 or more days of moderate- or low-intensity activity of at least 30 minutes/day, or 5 or more days of any combination of low-, moderate-intensity or vigorous activity of at least $\mathrm{EE} \geq 600 \mathrm{MET} \cdot \mathrm{min} /$ week.

3. Low physical activity level (LPAL) - no physical activity reported or some activity reported but not enough to meet at least the MPAL criteria.

Quality of life was assessed using the World Health Organization Quality of Life (WHOQOL-BREF) instrument. ${ }^{45}$ WHOQOL-BREF comprises 26 items: two measuring GQOL 
and perceived health condition (PHC), respectively, which were examined separately, and 24 measuring quality of life in four broad domains: PHYD (seven items), PSYD (six items), SD (three items), and ED (eight items). Particular facets incorporated within the domains included the following:

1. Physical health: activities of daily living, dependence on medicinal substances and medical aids, energy and fatigue, mobility, pain and discomfort, sleep and rest, and work capacity.

2. Psychological: bodily image and appearance, negative feelings, positive feelings, self-esteem, spirituality/ religion/personal beliefs, thinking, learning, and memory and concentration.

3. Social relationships: personal relationships, social support, and sexual activity.

4. Environment: financial resources, freedom, physical safety and security, health and social care: accessibility and quality, home environment, opportunities for acquiring new information and skills, participation in and opportunities for recreation/leisure activities, physical environment (pollution/noise/traffic/climate), and transport.

Each item was scored from 1 to 5. Higher scores denoted higher quality of life and better perception of health condition. For the first two items, the numerical scores were the basis for further analysis. The scores to the remaining 24 items were transformed on a special 4- to 20-point scale. ${ }^{45}$ Additionally, the index of GQOL was expressed on a nominal scale. The results on a nominal scale (1-5 points) were then converted into sten scores (1-10 stens) according to the formula: $\mathrm{S}=5.5+2 \times \mathrm{ZZ}(\mathrm{S}-$ raw data after transformation and $\mathrm{ZZ}$ - raw scores multiplied by mean and standard deviation). Next, the obtained sten scores were used to categorize participants into groups with different ranges of perception of GQOL: $<6$ stens - low, 6 stens - medium, and $>6$ stens - high. ${ }^{46}$ The collected questionnaire data were cleaned and subjected to statistical analysis. The dependent variables included GQOL, perception of health condition, and quality of life in four domains: PHYD, PSYD, SD, and ED. The independent variable was the physical activity level (low, moderate, vigorous).

The statistical significance of differences between GQOL and health perception in groups of participants categorized according to their physical activity levels was measured with the Kruskal-Wallis one-way analysis of variance by ranks and multiple comparisons mean ranks post hoc tests. Multinomial logistic regression analysis was used to assess relationships between quality of life and physical activity levels. The level of statistical significance was set ex ante at $\alpha<0.05$. All statistical calculations were made using IBM SPSS Statistics 20.

\section{Results}

Among the older working-age respondents from Wrocław, the highest percentage (42.3\%) were individuals with a high level of physical activity, followed by $36.2 \%$ with a moderate level and $21.4 \%$ with a low level. Highly and moderately active individuals were significantly more numerous $(p<0.001)$ than participants with low levels of physical activity. The differences between the groups of moderately and highly physically active participants were statistically nonsignificant ( $p \geq 0.05$; Table 1 ).

The analysis of mean assessment values of particular quality of life domains in physical activity groups of Wrocław inhabitants aged 55-64 years revealed statistically significant differences between the groups. The highest quality of life (3.8 \pm 0.8 points) was indicated by individuals with high levels of physical activity, followed by those with low levels of physical activity ( $3.7 \pm 0.8$ points). The lowest quality of life (3.6 \pm 0.9 points) was marked by respondents featuring a moderate level of physical activity. The Kruskal-Wallis test $(H=48.6, p<0.001)$ indicated that the mean ranks of quality of life in groups according to physical activity levels differed significantly from one another. The $p$-values for post hoc multiple comparisons between mean ranks in particular groups revealed statistically significant differences between the quality of life of highly physically active individuals and that of those with moderate and low levels of physical activity. No such differences were noted between the moderately and the least physically active respondents (Table 2).

General health satisfaction was the highest among the most active respondents ( $3.7 \pm 0.9$ points), followed by the moderately ( $3.5 \pm 1.0$ points) and the least active Wrockaw respondents $(3.7 \pm 1.0$ points). The differences in perceived health status were statistically significant in groups of respondents with different levels of physical activity

Table I Number and percentage of respondents in groups with different levels of physical activity

\begin{tabular}{lll}
\hline Physical activity level & $\mathbf{n}$ & $\%$ \\
\hline LPAL & 217 & $21.4^{\mathrm{a}, *}$ \\
MPAL & 367 & $36.2^{\mathrm{b}, \mathrm{NS}}$ \\
HPAL & 429 & $42.3^{\mathrm{c}, *}$ \\
\hline
\end{tabular}

Notes: Significant differences $\left({ }^{*} p<0.00 \mathrm{I}\right)$ and no significant differences $\left({ }^{\mathrm{Ns}} p \geq 0.05\right)$ between participants. $\mathrm{n}$, number of respondents; \%, percentage of respondents. aLPAL vs MPAL. 'MPAL vs HPAL. 'HPAL vs LPAL.

Abbreviations: LPAL, low physical activity level; MPAL, moderate physical activity level; HPAL, high physical activity level. 
Table 2 Quality of life in groups of respondents with different levels of physical activity

\begin{tabular}{|c|c|c|c|c|c|c|c|c|}
\hline \multirow{2}{*}{$\begin{array}{l}\text { Quality } \\
\text { of life }\end{array}$} & \multirow{2}{*}{$\begin{array}{l}\text { Physical activity } \\
\text { level }\end{array}$} & \multirow[t]{2}{*}{$\overline{\mathbf{x}} \pm \mathbf{S D}$} & \multirow[t]{2}{*}{$\overline{\mathbf{x}} \mathbf{R}$} & \multirow[t]{2}{*}{$H$} & \multirow[t]{2}{*}{$p$-value } & \multicolumn{3}{|c|}{ Multiple comparisons mean ranks probability value } \\
\hline & & & & & & LPAL vs MPAL & LPAL vs HPAL & MPAL vs HPAL \\
\hline \multirow[t]{3}{*}{ GQOL } & LPAL & $3.7 \pm 0.8$ & 2,174 & 48.6 & $<0.001$ & $\geq 0.05$ & $<0.01$ & $<0.001$ \\
\hline & MPAL & $3.6 \pm 0.9$ & 2,103 & & & & & \\
\hline & HPAL & $3.8 \pm 0.8$ & 2,372 & & & & & \\
\hline \multirow[t]{3}{*}{$\mathrm{PHC}$} & LPAL & $3.5 \pm 1.0$ & 2,168 & 85.3 & $<0.001$ & $\geq 0.05$ & $<0.001$ & $<0.001$ \\
\hline & MPAL & $3.4 \pm 1.0$ & 2,055 & & & & & \\
\hline & HPAL & $3.7 \pm 0.9$ & 2,418 & & & & & \\
\hline \multirow[t]{3}{*}{ PHYD } & LPAL & $12.5 \pm 1.8$ & $2,|3|$ & 40.8 & $<0.001$ & $\geq 0.05$ & $<0.001$ & $<0.001$ \\
\hline & MPAL & $12.5 \pm 1.7$ & 2,122 & & & & & \\
\hline & HPAL & $12.8 \pm 1.8$ & 2,372 & & & & & \\
\hline \multirow[t]{3}{*}{ PSYD } & LPAL & $13.9 \pm 1.9$ & 2,187 & 41.2 & $<0.001$ & $\geq 0.05$ & $<0.01$ & $<0.001$ \\
\hline & MPAL & $13.7 \pm 2.0$ & 2,100 & & & & & \\
\hline & HPAL & $14.1 \pm 1.9$ & 2,368 & & & & & \\
\hline \multirow[t]{3}{*}{ SD } & LPAL & $14.9 \pm 2.7$ & 2,075 & 46.7 & $<0.001$ & $\geq 0.05$ & $<0.001$ & $<0.001$ \\
\hline & MPAL & $15.0 \pm 2.6$ & $2,|4|$ & & & & & \\
\hline & HPAL & $15.5 \pm 2.5$ & 2,378 & & & & & \\
\hline \multirow[t]{3}{*}{ ED } & LPAL & $13.3 \pm 2.3$ & 2,186 & 98.4 & $<0.001$ & $<0.01$ & $<0.001$ & $<0.001$ \\
\hline & MPAL & $13.0 \pm 2.3$ & 2,021 & & & & & \\
\hline & HPAL & $13.7 \pm 2.4$ & $2,44 I$ & & & & & \\
\hline
\end{tabular}

Notes: $\bar{x}$, mean; SD, standard deviation; $\bar{x} R$, mean ranks; $H$, Kruskal-Wallis test; $p$, Kruskal-Wallis test probability value.

Abbreviations: LPAL, low physical activity level; MPAL, moderate physical activity level; GQOL, general quality of life; HPAL, high physical activity level; PHC, perceived health condition; PHYD, physical domain; PSYD, psychological domain; SD, social domain; ED, environmental domain.

$(H=85.3, p<0.001)$. The post hoc comparison between the groups revealed differences in health status perception between the high- and moderate-activity groups and between the high- and low-activity groups ( $p<0.001$; Table 2$)$.

Statistically significant differences between groups with different physical activity levels were also noted in all four domains of quality of life assessment. The highest scores in WHOQOL domains were attained by respondents with the highest levels of physical activity. In the physical health domain and SD, the lowest quality of life was noted among the least physically active respondents, whereas in the PSYD and ED, the lowest scores were given by individuals with moderate levels of physical activity. In the groups with different levels of physical activity, the mean ranks of all quality of life domains differed significantly from one another $(p<0.001)$. Intergroup post hoc comparisons revealed statistically significant differences between the groups with LPAL and HPAL and MPAL and HPAL and in the case of the ED also between groups with LPAL and MPAL (Table 2).

Table 3 shows the results of multinomial logistic regression analysis illustrating relationships between physical activity and quality of life of older working-age respondents from Wrocław. The reference category for the model trichotomous dependent variable, ie, quality of life, was its low level. The values of goodness-of-fitting model $\left(\chi^{2}=49.7\right)$ and test probability $(p<0.001)$ indicate that the specific model

Table 3 Multinomial logistic regression analysis parameters of dependent variable: overall quality of life

\begin{tabular}{|c|c|c|c|c|c|c|c|c|}
\hline \multirow{2}{*}{$\begin{array}{l}\text { Overall quality } \\
\text { of life }\end{array}$} & \multirow[t]{2}{*}{ Parameter } & \multirow[t]{2}{*}{$\beta$} & \multirow[t]{2}{*}{ SE } & \multirow[t]{2}{*}{ Wald $\chi^{2}$} & \multirow[t]{2}{*}{$p$-value } & \multirow[t]{2}{*}{ OR } & \multicolumn{2}{|l|}{$\mathrm{Cl}$} \\
\hline & & & & & & & $-95 \%$ & $95 \%$ \\
\hline \multirow[t]{3}{*}{$\overline{A Q O L}$} & Intercept & 0.02 & 0.11 & 0.0 & 0.873 & & & \\
\hline & LPAL vs HPAL & -0.85 & 0.18 & 21.2 & $<0.001$ & 0.43 & 0.30 & 0.61 \\
\hline & MPAL vs HPAL & -0.27 & 0.15 & 3.0 & 0.085 & 0.77 & 0.57 & 1.04 \\
\hline \multirow[t]{3}{*}{ HQOL } & Intercept & -0.83 & 0.14 & 36.9 & $<0.001$ & & & \\
\hline & LPAL vs HPAL & -1.95 & 0.37 & 27.7 & $<0.001$ & 0.14 & 0.07 & 0.30 \\
\hline & MPAL vs HPAL & -0.56 & 0.22 & 6.7 & 0.010 & 0.57 & 0.37 & 0.87 \\
\hline
\end{tabular}

Notes: The reference category for the dependent variable is LQOL, $\chi^{2}=49.7$, and $p<0.001$. $\beta$, assessment value of model parameters; SE, asymptotic standard error $\beta$; Wald $\chi^{2}$, parameter significance; $p$, probability level for Wald $\chi^{2}$.

Abbreviations: OR, odds ratio; Cl, confidence interval; AQOL, average quality of life; LPAL, low physical activity level; HPAL, high physical activity level; MPAL, moderate physical activity level; HQOL, high quality of life; LQOL, low quality of life. 
was significantly different from the one containing only the intercept parameter, and the level of physical activity significantly affected the quality of life in a given study group.

In the group of older working-age respondents, the odds that they assessed their quality of life as medium (not low) were $57 \%$ lower among the least physically active respondents and $23 \%$ lower among the moderately active respondents. The odds that the respondents would assess their quality of life as high (not low) were more than seven times lower (odds ratio $[\mathrm{OR}]=0.14$ ) in respondents with low physical activity than those with high levels of physical activity. As for the participants featuring a moderate level of physical activity, these odds were two times lower than in people with high levels of physical activity ( $\mathrm{OR}=0.57$; Table 3 ).

\section{Discussion}

The results of the present study showed that the physical activity level determined the quality of life in older workingage populations. Perceived GQOL, health status, and quality of life in the PHYD, PSYD, SD and ED were assessed as the highest by the most physically active respondents. Statistically significant correlations were also found between GQOL and the physical activity level. Furthermore, the odds of high assessment of GQOL were the highest among the most active individuals, followed by moderately active individuals, and were the lowest among the least physically active respondents.

High assessments of overall quality of life by individuals participating in properly dosed resistance training programs, compared with controls, were also noted by RamirezCampillo et al. ${ }^{36}$ Considering the study results indicating positive relationships between perceived quality of life and physical activity, the lack of movement - which is fairly common among older working-age people - should be treated as a worrisome trend. This observation was shared by Brown et al, ${ }^{47}$ who found that only $\sim 40 \%$ of people older than 50 years followed health recommendations regarding physical activity. Similar results were achieved by Puciato et al, ${ }^{31}$ Schneider and Becker, ${ }^{32}$ and Ignasiak et al. ${ }^{33}$

Some earlier studies also indicated positive links between satisfaction with one's own health and physical activity. ${ }^{34,38,48}$ They may have resulted from the usually better health status of physically active people than non-active ones. ${ }^{8,16,19,20}$ However, as shown by Kaczmarek et al, ${ }^{49}$ perceived health status not only depends on objective but also subjective factors, ie, psychological, social, and cultural. It is also affected by one's lifestyle and socioeconomic status. According to Wojszel, ${ }^{50}$ perceived health status is the best determinant of auspicious aging.
Thus, in older working-age populations, physical activity can play a preventive role and contribute to their better coping with the characteristic symptoms of aging.

The study of the Wrocław population also confirmed positive effects of physical activity on the PHYD of quality of life, as noted by other authors. ${ }^{34,40,51}$ Better physical health and physical fitness and performance of active individuals have a positive influence on their locomotive and self-maintenance skills as well as the ability to perform professional duties and domestic chores. ${ }^{5,8,27}$ Some authors even indicated potential, indirect links between quality of life and human functional traits. ${ }^{7,52}$ In addition, physical activity was shown to have a positive effect on sleep sufficiency in the elderly. ${ }^{53,54}$

The present study, as well as some earlier research, revealed positive relationships between physical activity and the PSYD of quality of life $\mathrm{e}^{34,41,55,56}$ Some authors suggest that the psychological quality of life is only positively affected by moderate- and high-intensity exercises. ${ }^{36,51}$ Researchers have also documented the positive role of physical activity as a factor enhancing the prevention or treatment of depression, ${ }^{57,58}$ anxiety, ${ }^{59}$ or other neurological disorders. ${ }^{60}$ The present study also confirms positive relationships between the SD of quality of life and physical activity. This is highly significant since people aged 55-64 years usually demonstrate the first symptoms of body aging, involution of performance skills, or sexual problems. All of them can have a negative impact on one's functioning in society, interpersonal relations, or fulfilment of professional duties. In the SD, physical activity can play both the preventive and therapeutic roles. Authors have confirmed the positive impact of physical activity on prevention or treatment of occupational burnout. ${ }^{61}$ Dębska and Mazurek ${ }^{37}$ also showed that physically active people can positively influence one's future and career concerns. The positive effects of physical activity on the SD were also noted by Guimarães and Baptista ${ }^{39}$ and Krzepota et al. ${ }^{34}$

So far there have been very few studies investigating positive relationships between quality of life in its ED and physical activity. Some authors point to higher levels of physical activity among individuals with enough leisure time or with sufficient material resources ${ }^{62}$ as components of quality of life in its ED. An earlier study by one of the authors of the present work $^{63}$ showed that having leisure and taking advantage of leisure opportunities constitute one of the most important determinants of quality of modern life.

A strong point of the present study is the comprehensive assessment of quality of life in older working-age people. Earlier studies usually focused on pre- or post-working age populations; a few were concerned with Poland or other 
countries of Central Europe. The high dynamics of social and economic changes related to the transformation from centrally planned to free market economy and gradual convergence with the most highly developed countries makes this part of Europe an interesting research area. The study also used novel methodology of data analysis regarding the GQOL index.

A drawback of the present study is its spatial limitation to one city only. Prospective research must cover the whole of Poland and other countries of Central Europe. Another limitation of the study is its cross-sectional character. Prospective continuous surveys will allow a systematic analysis of physical activity levels and their relationships with the quality of life of Wrocław residents as well as identify certain tendencies that may occur with age. The use of the short IPAQ version in the study confined the analysis of physical activity to a weekly basis only. In future, researchers should make use of tools allowing measurements of physical activity in different areas of life, eg, leisure, professional work, during moving, or performing domestic chores as well as examining the forms of performed physical activity. According to Valadares et al, ${ }^{64}$ the relationships between quality of life and physical activity may be different in different domains. In addition, a certain shortcoming of the study could have been the examination of an entire older working-age population sample of Wrocław regardless of their sex, education, occupation, or income. The significance of these socioeconomic determinants of quality of life was highlighted by Chen et al. ${ }^{2}$

\section{Conclusion}

The results of the present study confirm positive relationships between physical activity and quality of life in senior working-age people. The study revealed that the level of physical activity did have an impact on different domains of quality of life of the examined population. Previous studies failed to provide such unambiguous results, especially in the SD and ED. An original conclusion from the study is the increased odds of high assessment of perceived GQOL together with higher levels of physical activity. Undertaking physical activity by senior citizens has preventive and therapeutic effects, and it improves the quality of their life as compared with their physically less active counterparts. Since quality of life improvement is one of key objectives in the development strategy of many countries and regions, all related planned tasks should also focus on improvement of physical activity. Important locations for implementation of such tasks, especially in relation to older working-age people, are their places of employment, which could provide leisure facilities or bicycle storage rooms, organize recreational activities, promote disease-prevention programs for employees and their families, or perhaps, sponsor amateur sports clubs that company employees could join.

\section{Disclosure}

The authors report no conflicts of interest in this work.

\section{References}

1. Bączkowicz D, Majorczyk E, Kręcisz K. Age-related impairment of quality of joint motion in vibroarthrographic signal analysis. Biomed Res Int. 2015;2015:591707.

2. Chen Y, Hicks A, While A. Quality of life and related factors: a questionnaire survey of older people living alone in Mainland China. Qual Life Res. 2014;23(5):1593-1602.

3. Fassino S, Leombruni P, Daga G, Brustolin A, Rovera G, Fabris F. Quality of life in dependent older adults living at home. Arch Gerontol Geriatr. 2002;35(1):9-20.

4. Groessl EJ, Kaplan RM, Barrett-Connor E, Ganiats TG. Body mass index and quality of well-being in a community of older adults. $\mathrm{Am} J$ Prev Med. 2004;26(2):126-129.

5. Rożek-Piechura K, Ignasiak Z, Sławińska T, Piechura J, Ignasiak T. Respiratory function, physical activity and body composition in adult rural population. Ann Agric Environ Med. 2014;21(2):369-374.

6. Skrzek A, Ignasiak Z, Koziel S, Sławińska T, Rożek K. Differences in muscle strength depend on age, gender and muscle functions. Isokinet Exerc Sci. 2012;20(3):229-235.

7. Skrzek A, Pridalova M, Sebastjan A, et al. Fine motor skills of the hands in Polish and Czech female senior citizens from different backgrounds. Aging Clin Exp Res. 2015;27(4):491-498.

8. Stemplewski R, Maciaszek J, Salamon A, Tomczak M, Osinski W. Effect of moderate physical exercise on postural control among 65-74 years old men. Arch Gerontol Geriat. 2012;54(3):279-283.

9. Aronow W. Exercise therapy for older persons with cardiovascular disease. Am J Geriat Cardiol. 2011;10:245-252.

10. Carvalho A, Barbirato D, Araujo N, et al. Comparison of strength training, aerobic training, and additional physical therapy as supplementary treatments for Parkinson's disease: pilot study. Clin Interv Aging. 2015;10:183-191.

11. Castillo-Rodriguez A, Chinchilla-Minguet JL. Cardiovascular program to improve physical fitness in those over 60 years old - pilot study. Clin Interv Aging. 2014;9:1269-1274.

12. Cichocki M, Quehenberger V, Zeiler M. Effectiveness of a low-threshold physical activity intervention in residential aged care - results of a randomized controlled trial. Clin Interv Aging. 2015;10:885-895.

13. Fransson E, de Faire U, Ahlbom A, Reuterwall C, Halquist J, Alfredsson L. The risk of acute myocardial infarction: interactions of types of physical activity. Epidemiology. 2004;15(5):573-582.

14. Goran M, Ball G, Cruz M. Obesity and risk of type 2 diabetes and cardiovascular disease in children and adolescents. J Clin Endocr Metab. 2003;88(4):1417-1427.

15. Kohl H. Physical activity and cardiovascular disease: evidence for a dose response. Med Sci Sport Exer. 2001;33(6 Suppl):472-483.

16. Mynarski W, Psurek A, Borek Z, Rozpara M, Grabara M, Strojek K. Declared and real physical activity in patients with type 2 diabetes mellitus as assessed by the International Physical Activity Questionnaire and Caltrac accelerometer monitor: a potential tool for physical activity assessment in patients with type 2 diabetes mellitus. Diabetes Res Clin Pr. 2012;98(1):46-50.

17. Nawrocka A, Mynarski W, Powerska A, Grabara M, Groffik D, Borek Z. Health-oriented physical activity in prevention of musculoskeletal disorders among young Polish. Int J Occup Med Environ Health. 2014;27:28-37. 
18. Ramalho JR, Mambrini JV, Cesar CC. Physical activity and all-cause mortality among older Brazilian adults: 11-year follow-up of the Bambui Health and Aging Study. Clin Interv Aging. 2015;10:751-758.

19. Skrzek A, Ignasiak Z, Sławińska T, et al. Structural and functional markers of health depending on lifestyle in elderly women from Poland. Clin Interv Aging. 2015;10:781-793.

20. Wróblewska I, Oleśniewicz P, Kurpas D, Sołtysik M, Błaszczuk J. Analysis of spirometry results in hospitalized patients aged over 65 years. Clin Interv Aging. 2015;10:1071-1076.

21. Eggenberger P, Schumacher V, Angst M, Theill N, de Bruin ED. Does multicomponent physical exercise with simultaneous cognitive training boost cognitive performance in older adults? A 6-month randomized controlled trial with a 1-year follow-up. Clin Interv Aging. 2015;10: 1335-1349.

22. Guszkowska M, Sionek S. Changes in mood states and selected personality traits in women participating in a 12 -week exercise program. Hum Mov. 2009;10:163-169.

23. Iwasaki Y. Testing independent and buffer models of the influence of leisure participation on stress-coping and adaptational outcomes. J Park Recreat Adm. 2002;20:90-126.

24. O’Connor P, Smith J, Morgan W. Physical activity does not provoke panic attacks in patients with panic disorder. A review of the evidence. Anxiety Stress Copin. 2000;13:333-353.

25. Rahe J, Petrelli A, Kaesberg S, Fink GR, Kessler J, Kalbe E. Effects of cognitive training with additional physical activity compared to pure cognitive training in healthy older adults. Clin Interv Aging. 2015; 10:297-310.

26. Shin K, Kang Y, Park H, Heitkemper M. Effects of exercise program on physical fitness, depression and self-efficacy of low-income elderly women in South Korea. Public Health Nurs. 2009;26(6): 523-531.

27. Milanovic Z, Pantelic S, Trajkovic N, Sporis G, Kostic R, James N. Age-related decrease in physical activity and functional fitness among elderly men and women. Clin Interv Aging. 2013;8:549-556.

28. Halloway S, Wilbur J, Schoeny M, Arfanakis K. Effects of endurancefocused physical activity interventions on brain health: a systematic review. Biol Res Nurs. 2017;19:53-64.

29. Kirk-Sanchez N, McGough E. Physical exercise and cognitive performance in the elderly: current perspectives. Clin Interv Aging. 2014;9: 51-62.

30. Martinez P, Lopez J, Hernandez A, Dantas E. Effect of periodized water exercise training program on functional autonomy in elderly women. Nutr Hosp. 2015;31(1):351-356.

31. Puciato D, Rozpara M, Mynarski W, Łoś A, Królikowska B. Physical activity of adult residents of Katowice and selected determinants of their occupational status and socio-economic characteristics. Med Pr. 2013;64:649-657.

32. Schneider S, Becker S. Prevalence of physical activity among the working population and correlation with work-related factors. Results from the first German National Health Survey. J Occup Health. 2005;47(5):414-423.

33. Ignasiak Z, Sławińska T, Dąbrowski A, Rowiński R. The structure of physical activity in seniors from lower Silesia. Rocz Panstw Zakl Hig. 2013;64(1):67-73.

34. Krzepota J, Biernat E, Florkiewicz B. The relationship between levels of physical activity and quality of life among students of the University of Third Age. Central Eur J Public. 2015;23(4):335-339.

35. Schoenfelder D, Rubenstein L. An exercise program to improve fallrelated outcomes in elderly nursing home residents. Appl Nurs Res. 2004;17(1):21-31.

36. Ramirez-Campillo R, Diaz D, Martinez-Salazar C, et al. Effects of different doses of high-speed resistance training on physical performance and quality of life in older women: a randomized controlled trial Clin Interv Aging. 2016;11:1797-1804.

37. Dębska G, Mazurek H. Factors related to changes in the quality of life among Polish adolescents and adults with cystic fibrosis over a 1-year period. Patient Prefer Adherence. 2015;9:1763-1770.
38. Quehenberger V, Cichocki M, Krajic K. Sustainable effects of a lowthreshold physical activity intervention on health-related quality of life in residential aged care. Clin Interv Aging. 2014;9:1853-1864.

39. Guimarães A, Baptista F. Influence of habitual physical activity on the symptoms of climacterium/menopause and the quality of life of middle-aged women. Int J Wom Health. 2011;3:319-328.

40. Marie-Ludivine CD, Papouin G, Saint-Val P, Lopez A. Effect of adapted karate training on quality of life and body balance in 50-year-old men. Open Access J Sports Med. 2010;1:143-150.

41. Chai W, Nigg C, Pagano I, Motl R, Horwath C, Dishman R. Associations of quality of life with physical activity, fruit and vegetable consumption, and physical inactivity in a free living, multi-ethnic population in Hawaii: a longitudinal study. Int J Behav Nutr Phys Act. 2010;7:83.

42. Peddle C, Au H, Courneya K. Associations between exercise, quality of life, and fatigue in colorectal cancer survivors. Dis Colon Rectum. 2008;51(8):1242-1248.

43. Polechoński J, Mynarski W, Nawrocka A. Applicability of pedometry and accelerometry in the calculation of energy expenditure during walking and Nordic walking among women in relation to their exercise heart rate. J Phys Ther Sci. 2015;27(11):3525-3527.

44. International Physical Activity Questionnaire. Available from: https:// sites.google.com/site/theipaq/. Accessed October 17, 2014.

45. The World Health Organization Quality of Life (WHOQOL) [homepage on the Internet]. Available from: http://www.who.int. Accessed October 10, 2014.

46. Brzeziński J. Elementy metodologii badań psychologicznych [Introduction to the Methodology of Psychological Reserach]. Warsaw: PWN; 1984:541-545.

47. Brown D, Yore M, Ham S, Macera C. Physical activity among adults > or=50 yr with and without disabilities, BRFSS 2001. Med Sci Sports Exerc. 2005;37(4):620-629.

48. Ormel J, Kempen G, Deeg D, et al. Functioning, wellbeing and health perception in late middle-aged and older people: comparing the effects of depressive symptoms and chronic medical conditions. J Am Geriatr Soc. 1999;46:39-48.

49. Kaczmarek M, Skrzypczak M, Maćkowiak K. The effects of socioeconomic and lifestyle factors on the subjective perception of health in ageing males. Gerontol Pol. 2006;14(2):284-290.

50. Wojszel B. Health determinants of quality of life and health status of older people. Gerontol Pol. 1996;4:28-33.

51. Omorou Y, Erpelding M, Escalon H, Vuillemin A. Contribution of taking part in sport to the association between physical activity and quality of life. Qual Life Res. 2013;22(8):2021-2029.

52. Puciato D, Mynarski W, Rozpara M, Borysiuk Z, Szyguła R. Motor development of children and adolescents aged 8-16 years in view of their somatic build and objective quality of life of their families. J Hum Kinet. 2011;28:45-53.

53. Loprizni P, Cardinal B. Association between objectively-measured physical activity and sleep NHANES 2005-2006. Ment Health Phys Act. 2011;4:65-69.

54. Tsunoda K, Kitano N, Kai Y, et al. Prospective study of physical activity and sleep in middle-aged and older adults. Am J Prev Med. 2015; 48(6):662-673.

55. Borowiak E, Kostka T. Predictors of quality of life in older people living at home and in institutions. Aging Clin Exp Res. 2004;16(3): 212-220.

56. Kostka T, Jachimowicz V. Relationship of quality of life to dispositional optimism, health locus of control and self-efficacy in older subjects living in different environments. Qual Life Res. 2010;19(3):351-361.

57. Teychenne M, Ball K, Salmon J. Physical activity and likelihood of depression in adults: a review. Prev Med. 2008;46(5):397-411.

58. Robertson R, Robertson A, Jepson R, Maxwell M. Walking for depression or depressive symptoms: a systematic review and meta-analysis. Ment Health Phys Act. 2012;5:66-75.

59. Dziubek W, Kowalska J, Kusztal M, et al. The level of anxiety and depression in dialysis patients under-taking regular physical exercise training a preliminary study. Kidney Blood Press Res. 2016;41:86-98. 
60. Lancer R, Motta R, Lancer D. The effect of aerobic exercise on obsessive-compulsive disorder, anxiety and depression: a preliminary investigation. Behav Ther. 2007;30:53-62.

61. Toker S, Biron M. Job burnout and depression: unraveling their temporal relationship and considering the role of physical activity. $J \mathrm{Appl}$ Psychol. 2012;97(3):699-710.

62. Rennemark M, Berggren T. Relationships between work-status and leisure lifestyle at the age of 60 years old. Eur J Ageing. 2016;3:82-88.
63. Puciato D. Leisure as determinant of life quality exemplified by empirical research. Stud Works Coll Manage Finance. 2009;95:97-109.

64. Valadares A, Carvalho E, Costa-Paiva L, Morais S, Pinto-Neto A. Association between different types of physical activities and quality of life in women aged 60 years or over. Rev Assoc Med Bras. 2011;57(4): $450-455$.

\section{Publish your work in this journal}

Clinical Interventions in Aging is an international, peer-reviewed journal focusing on evidence-based reports on the value or lack thereof of treatments intended to prevent or delay the onset of maladaptive correlates of aging in human beings. This journal is indexed on PubMed Central, MedLine,
CAS, Scopus and the Elsevier Bibliographic databases. The manuscript management system is completely online and includes a very quick and fair peer-review system, which is all easy to use. Visit http://www.dovepress. com/testimonials.php to read real quotes from published authors. 